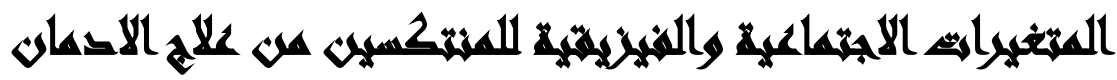

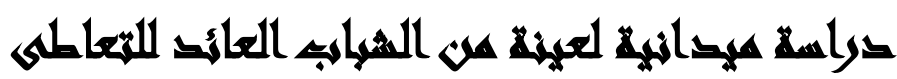 \\ [1 r
}

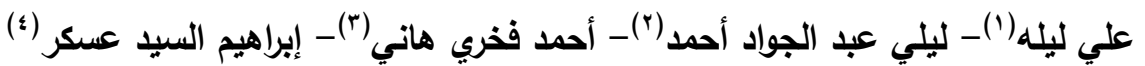

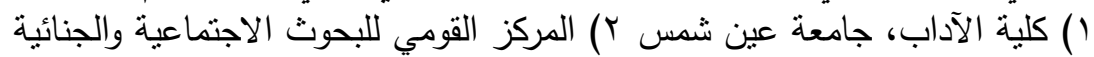

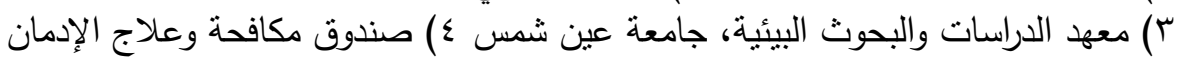

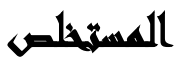

تهدف الدراسة الحالية إلى الكثف عن العوامل الاجتماعية والفيزيقية السائدة والمؤدية إلي الي العيا الانتكاسة وترتيب تللك العوامل من جانب خطورتها، كذلك الكثف الكف عن العوامل المشتركة

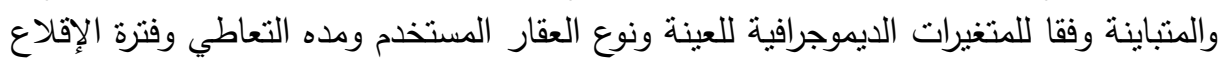

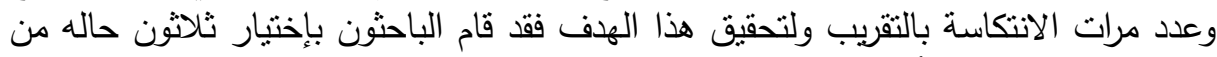

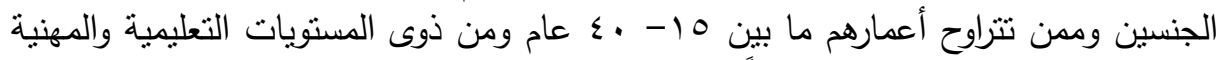

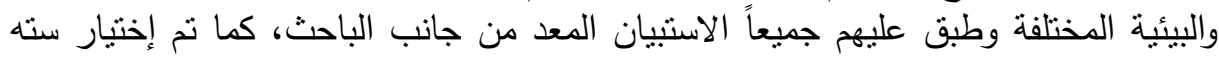

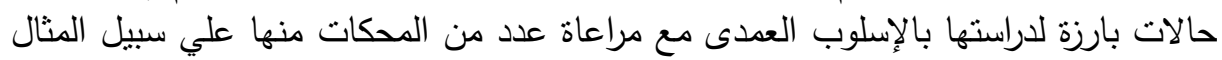

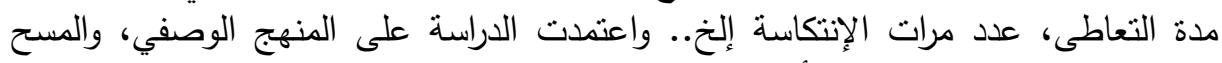

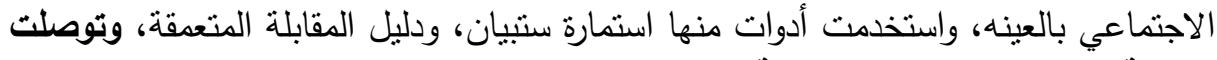

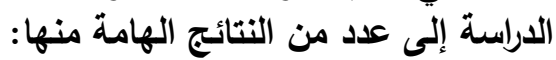

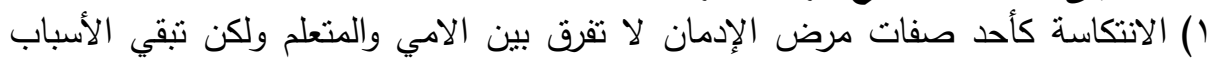

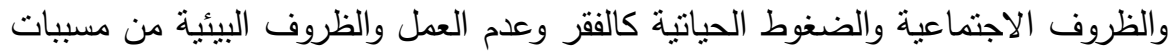

r) الحرفيين من أكثر الفئات المعرضه للانحراف والوقوع في براثن المخدرات وأكثرها عرضة

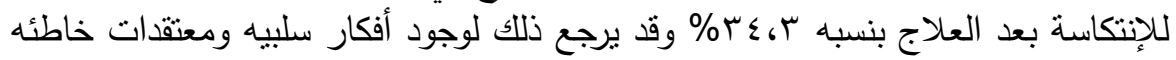

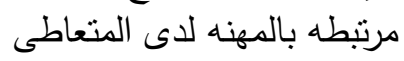

r) هناك الكثير من المعتقدات الخاطئة المرنبطة بأذهان الثباب تجعلهم يقدمون علي تعاطي

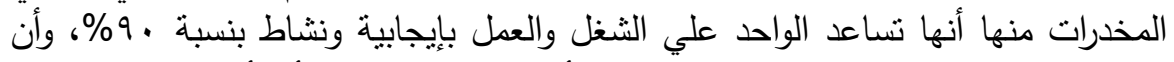

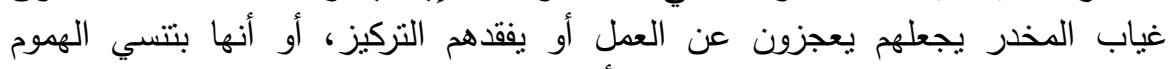

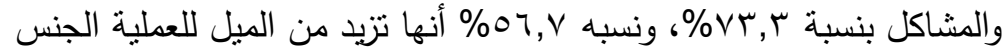

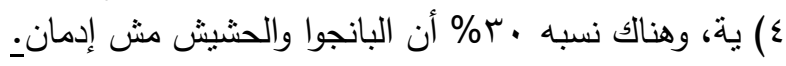

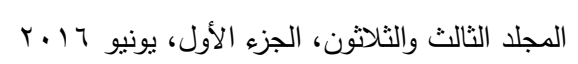




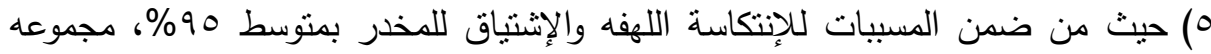

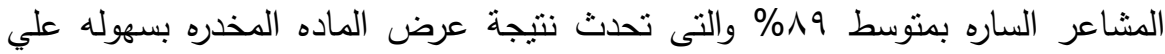

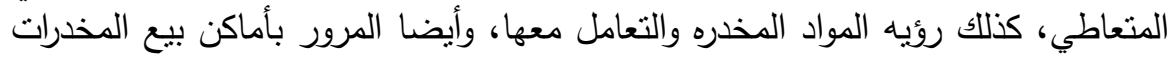

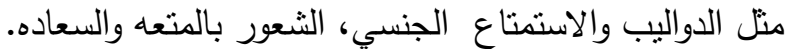

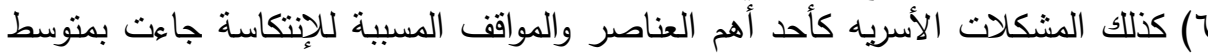
• . مواجهاه متل هذه المشكلات وتداعياتها.

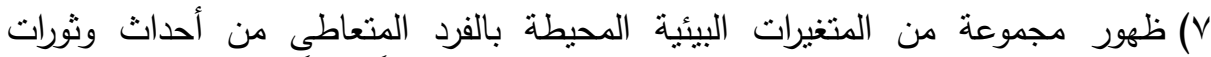
مجتمعية وثقافات وقيم جديدة عن المجتمع، كان لها دوراً كبيراً فى حدوث الفئ الإنتكاسة

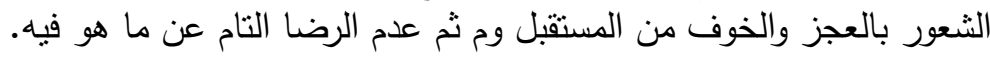

\section{$\cos$}

تسعي غالبية المجتمعات في الوقت الحاضر إلي تحقيق التتمية والتقدم والرفاهية والسلام الاجتماعي لأبنائها وذلك من خلال تتفيذ سياسات وبرامج تتمويـة متعددة ومواكبة لاتجاهات

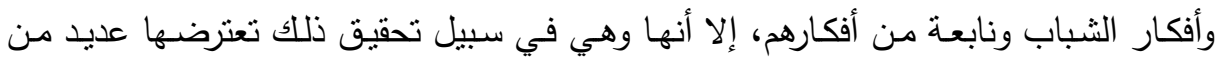
العقبات والمشكلات التي منها مـا هو مرتبط بصفة خاصـة بالمجتمعـات المتتاميـة ( الأميـة،

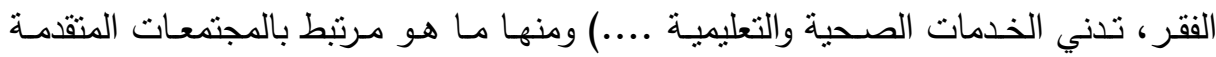
(الجريمة، العنف، الانتحار ) ومنها ما هو مشترك بين نللك المجتمعات وإن اختلفت في نسب ومعدلات انتشـارها ومدى خطواتها ( البطالة، الإيدز ، الإرهاب ، الجريمـة، العنف، تعاطي

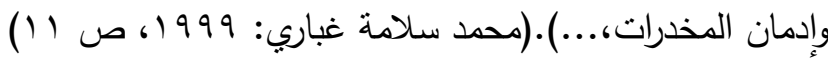
وتعد مشكلة إدمان المخدرات Drug Addiction واحدة من أخطر المشكلات النفسية والاجتماعية التي تواجه غالبية (إن لم يكن كل) المجتمعات، فمجوع الأحداث التي مرت بها مصر خلال ثورات الربيع العربي يعد بمثابة مناخ طبيعي لانتشار المخدرات، وبالتالي تعاطيها

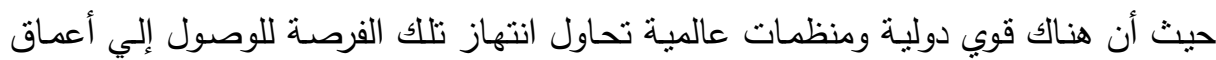

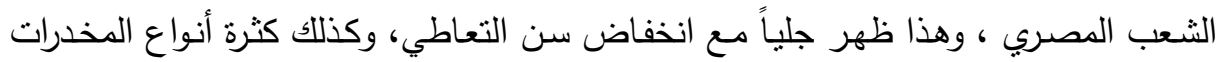
واستحداث أنواع جديدة لتسيطر علي السوق المحلية مستخدمين في ذلك سوء الأوضاع الأمنية 
والاجتماعية والاقتصادية وكذلك الأوضـاع البيئية والثقافيـة المحيطة بأذهان الثباب وقدرتهم

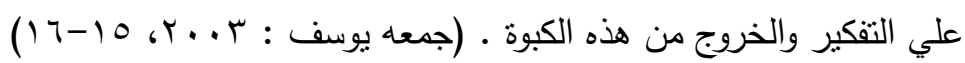

\section{هشعلة الصراسمة}

نتيجة للمستجدات المجتمعية الحديثة ظهرت مواد نفسية أثند خطورة منل الهيروين والكوكايين وعقاقير مؤثرة علي الحالة النفسية والعصبية مقارنة بالمواد المخدرة التي كانت

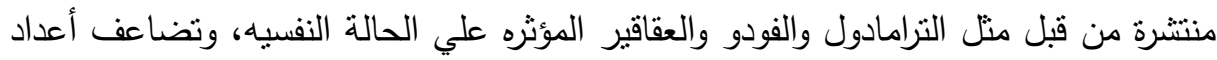
القضايا والمتهمين بها خلال عام ع ا ب ب وهذا يؤكد مدي خطور المشكلة وارتباطها بكل فئات المجتمع، حيث شيوع الظاهرة بين مختلف الطبقات المهنية والفئات والأعمار.(تقرير الإداره

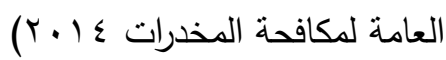
يشكل علاج الإدمان أحد المكونات الرئيسة في جهود خفض الطلب علي المخدرات،

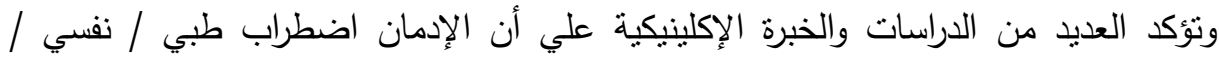
اجتماعي يستحق العلاج، ولما كان الإدمان اضطراباً يتميز بالانتكاس المتكرر، كانت الوقاية

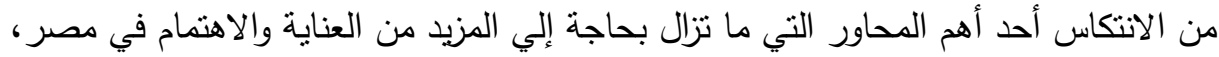
وتحث مناحي الوقاية من الانتكاس علي تعليم المرضي التركيز علي استراتيجيات تجنب

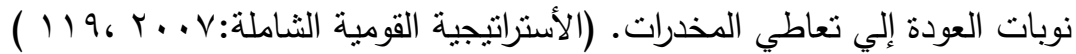
وعلى ذلـك يتحـد موضـوع الدارسـة حـول " دراسـة المتغيرات الإجتماعيـة والمتغيرات الديموجرافية وإرتباطها بدرجة الإنتكاسة لدى الأفراد العائدين للتعاطى بعد العلاج من الإدمان بمـا يسـهم في فهم أعمق لعملية الإنتكاسـة ويسـاعد فى رسم استراتيجية المواجهة الوقائيـه

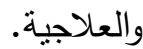


مجلة العلوم البيئية

معهد الدراسات والبحوث البيئية - جامعة عين شمس ليه

\section{تماؤلايش السراسة}

1- إلى أى مدى توجد علاقه بين الخصائص الديموجرافيه للعائدين للتعاطى ودرجه إنتكاستهر

$$
\text { بعد التعافي من الإدمان؟ }
$$

r- إلى أى مدى توجد علاقهه بين المعتقدات الخاطئه والثـائعه عن المخدرات لدى العائدين

$$
\text { للتعاطى ودرجه إنتكاستهم بعد التعافي من الإدمان؟ }
$$

ץ- إلى أى مدى توجد علاقه بين مسبيات الإنتكاسه لدى العائدين للتعاطى ودرجه إنتكاستهم

$$
\text { بعد التعافي من الإدمان؟ }
$$

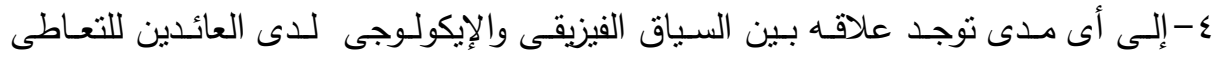

(المنطقـة السـكنيه ، طبيعـة المكـان، خصـائص المسكن ، المسـنوي التعليهـي، المسـتوي

الاقتصادي، والخدمات المتوفرة فيها، معدلات الجريمه والإنحراف، توافر الماده المخدره)

$$
\text { ودرجه إنتكاستهم بعد التعافي من الإدمان }
$$

\section{أهمية التراسمة}

\section{1-الأهمية النظرية:}

أ- تعد مشكلة تعاطي وإدمان المخدرات من المشكلات المجتمعية التي تؤثثر علي بناء المجتمع وتقدم أفراده بما يترتب عليها من آثار اقتصادية، نفسية ، صحية، واجتماعية

$$
\text { وأخري بيئية علي كل من الفرد والمجتمع. }
$$

ب- زيادة خطورة هذه المشكلة علي المحيط العالمي والمحلي مما يترتب عليه زيادة في ولي ماني معدلات الجريمة والسرقات والإرهاب وغسيل الأموال داخل المجتمع وخارجه.

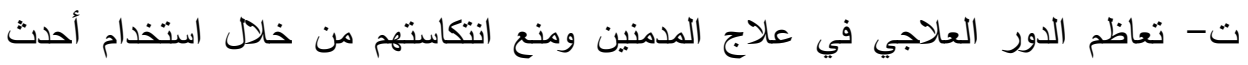
البرامج العلاجية مع الإهتمام بأهية التأهيل الاجتماعي والنفسي والبيئي والدمج المجتمعى للمرضي لعدم عودتهم إلي التعاطي والإدمان. 


\section{r-lالأهمية التطبيقية:}

أ- أهيـة دراسـة المشكلة مـن جيـع جوانبهـا العلاجيـة والتأهيليـة وذلك للحـد مـن انتشـارها

والانتكاسة منها.

ب- إلقاء الضوء علي عوامل الانتكاسة من الوجهة الاجتماعية والنفسية والفيزيقية، كما يدركها

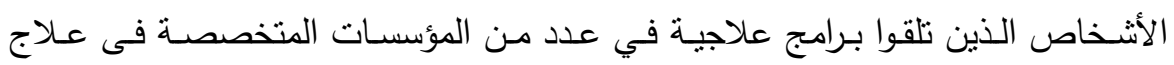

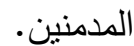

ج- الاستفادة في وضع وتدعيم برامج منع الانتكاسة ورفع مستويات الإقلاع عن التعاطي.

\section{أهساهث التراسلة}

1-التعرف علي ملامح التفاعل بين الخصائص الديموجرافية للعائدين للتعاطى أو المنتكسين.

r-التعرف علي الأفكار والتصورات الثائعة لدي العائدين للتعاطي حول مراحل الإنتكاسة

r- التعرف علي مسببات الإنتكاسة من وجهه نظر العائدين للتعاطي. ع - التعرف علي ملامح التفاعل بين السياق البيئي والايكولوجي لدى العائدين للتعاطى.

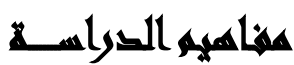

Relapse : الانتكاسةة

الانتكاسـة هـي انتهاك للقواعد التـي تحكم معدل أو نمط السـلوك المفروض القيـام بـــ

(ونشير هنا إلي الإقلاع الكامل عن تعاطي المواد المؤثرة نفسياً).

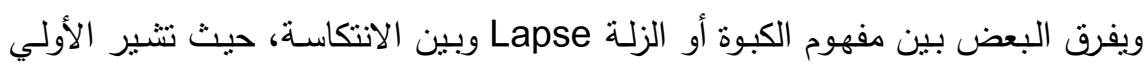

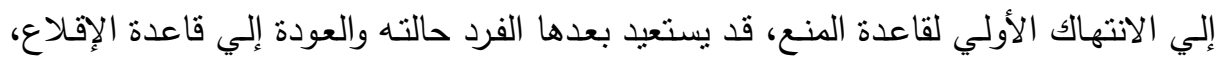

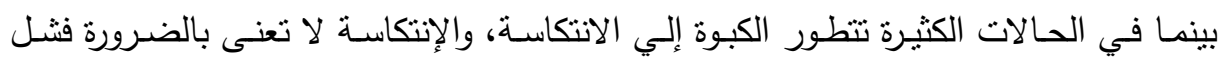

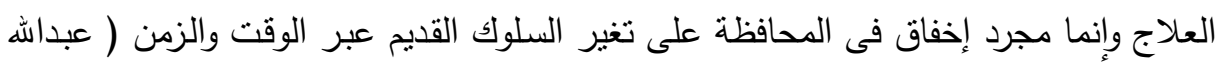

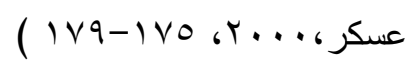


كما أن الإنتكاسة عملية دينامية وليس كيان ثابت ،أن هناك مراحل عدة للإنتكاسة وليس

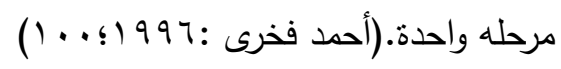

التعريف الإجرائى: هى العودة للتعاطى بعد مرور المتعاطى بخبرة نوقف نتيجة لعوامل متفاعلة

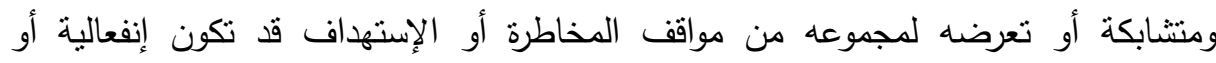

إجنماعية أو بيئية.

\section{r - الإعتماد على المواد المؤثرة نفسباً:}

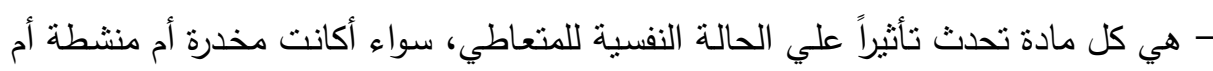

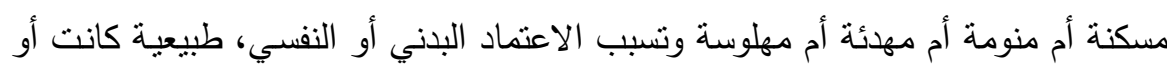

$$
\text { مخلقة. }
$$

- كمـا أنها مجموعـة من الظواهر الفيزيولوجيـة والسلوكية والمعرفية، التى يتخذ فيها نعاطى عقار ما أو صنف من العقاقير أسبقية لاى شخص معين أعلى بكثير من السلوكيات التى

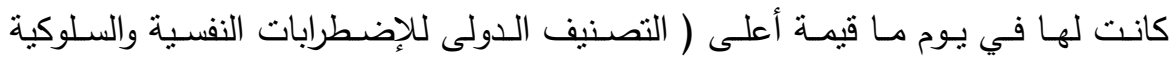

التعريـف الإجرائسى: هو شـعور المريض بوجود رغبـة قويـة أو الإضطرار إلي تعاطى المـادة

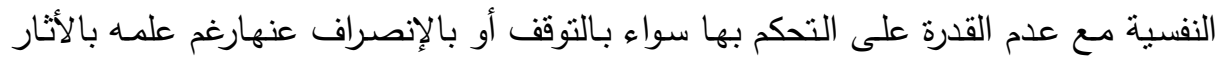
السلبية الناتجة عن تعاطيها ـ

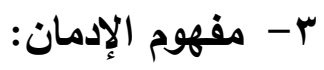

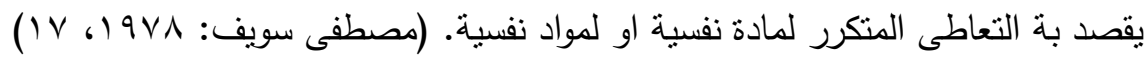

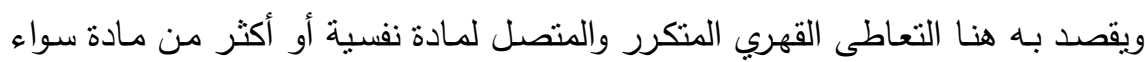

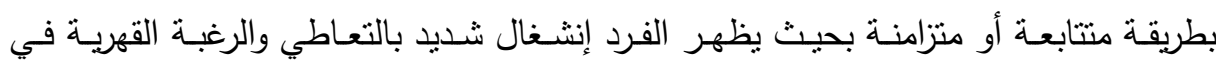

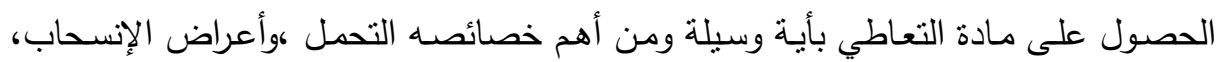

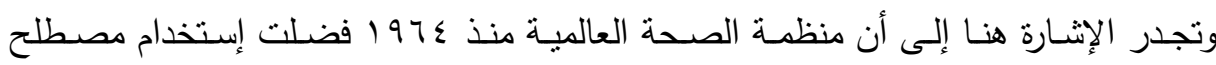

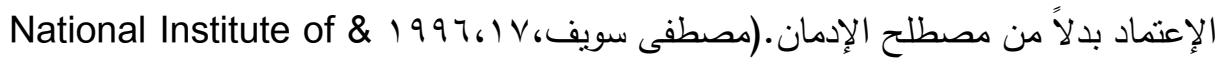

( Drug Abuse,2014 
ويؤكد التعريف العلمى لمنظمة الصحة العالمية على أن الأدمان هو حالة نفسية واحيانا عضوية تتنج عن تفاعل الكائن الحى مع العقار ومن خصائصها استجابات وانماط سلوكية مختلفة تشمل دائماً الرغبة الملحة فى تعاطى المخدر بصورة منصلة أو دورية للشعور بإثارة

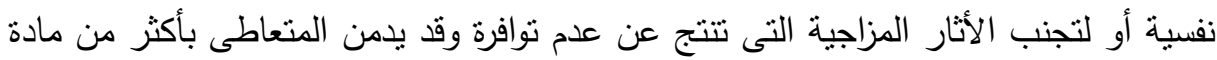
واحدة .

التعريـف الإجرائسى: يقصد بـه التعاطى المتكرر لمـادة أو أكثر من المواد المسببة للإعتمـاد

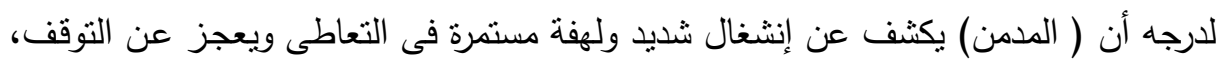

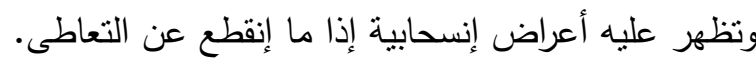

\section{ـ- مفهوم التعاطى:}

هو التتاول المتكرر لمادة نفسية إلى الحد الذى يوقع المتتاول فى أضرار ناجمة عن

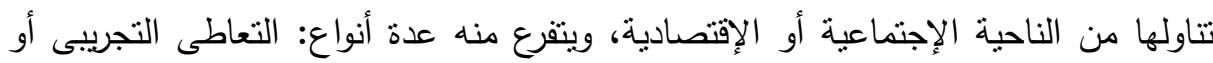
الإستكثافى، التعاطى بالمناسبة (المنقطع)، التعاطى المنتظم، التعاطى المتعدد للمواد النفسية.

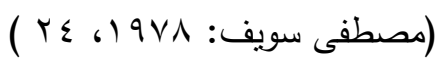

يقصــ بـة نتـاول المـواد المخدرة شكل تجريبـى أو متقطع أو بشكل منتظم ، وبالتـالى

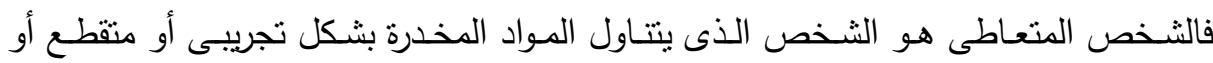

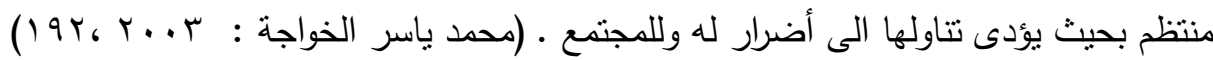

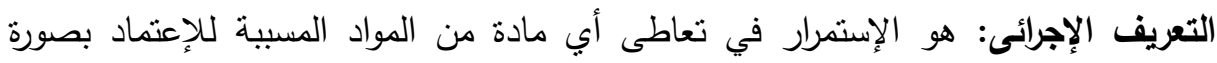

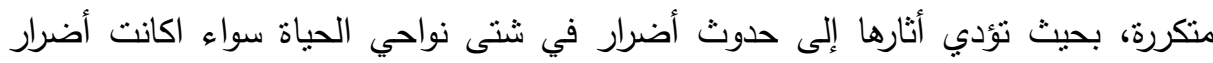
جسمية أو نفسية أو إجتماعية أوإقصادية. 


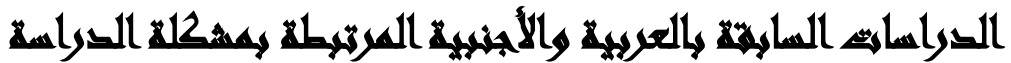

$$
\text { تمثلت الدراسات السابقة في ثلاث محاور : }
$$

المحور الأول: دراسات تناولت الأسباب والعوامل المرتبطة بالإنتكاسة والعودة

حيث أجرى جـون مـايير دراسـة (Majer, 2003) بعنوان: "هل القدرة الذانيـة علي السيطرة (ضبط النفس) علـي سـوك التعاطي تعد مصدراً مسـاعداً ؟" والتعامل مـع النتائج

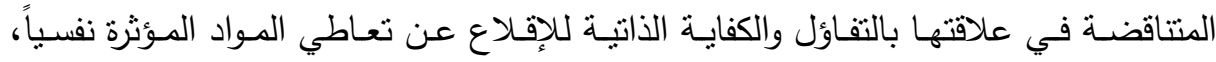

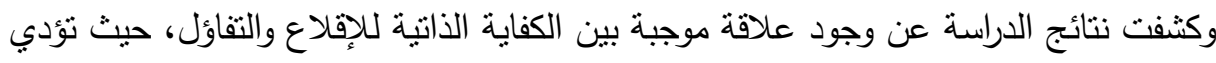

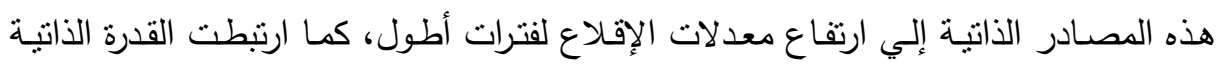

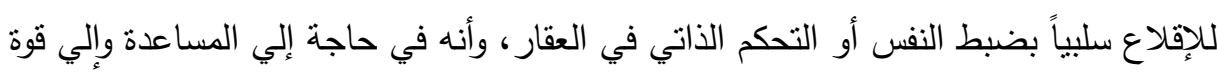
أبعد من قدراته الذاتية علي مساعدته في الاستمرار في الإقلاع.

Majer,John(2003):. by, www.findarticles.com

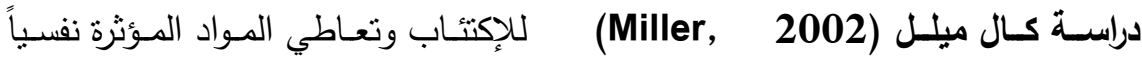

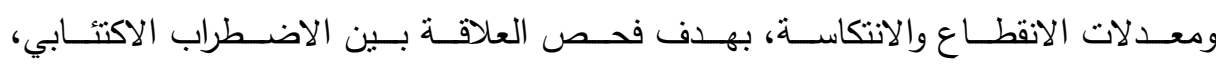

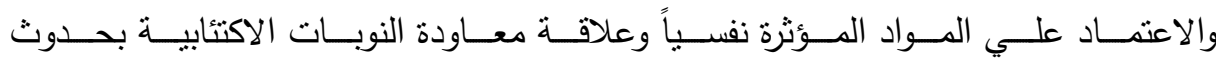

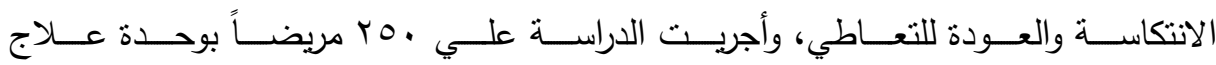

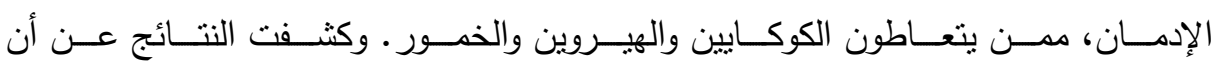

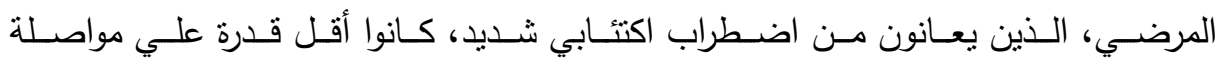

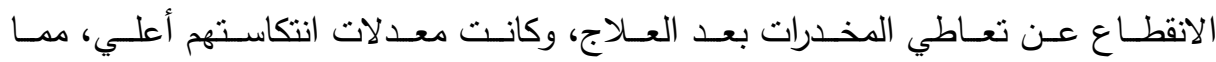

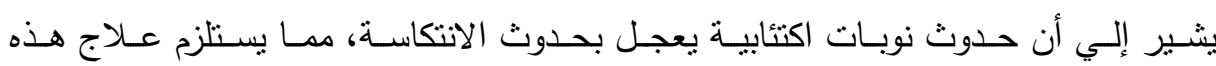

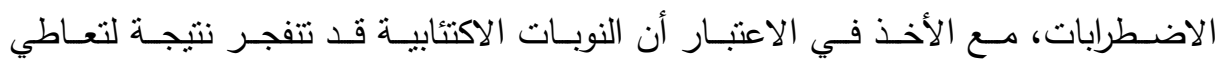
بعض أنواع المواد المؤثرة نفسياً. 


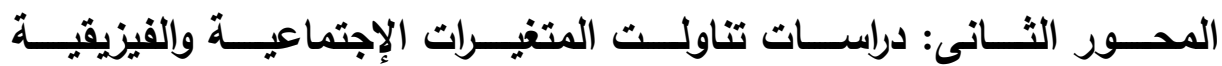

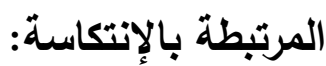

أجرى زهانج ويانج وليوان ( 2007 200

لمعرفه العوامل المؤثرة في نوعية الحياة لدى عينه من المعتمدين على الهيروين في ثنلاث

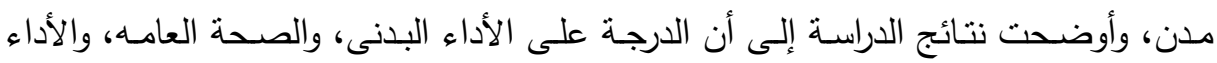

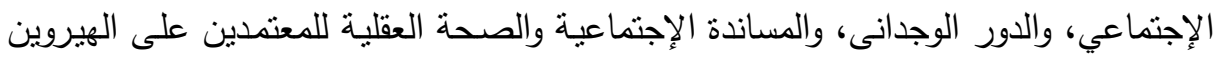

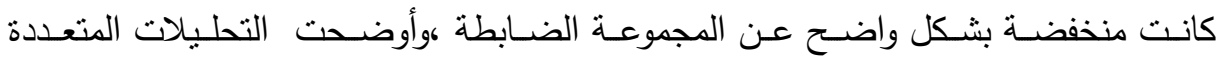
اللمتغيرات أن هناك عدداً من العوامل مثل العمر ، الخالة الزواجية والتعليم والوظيفة والدخل

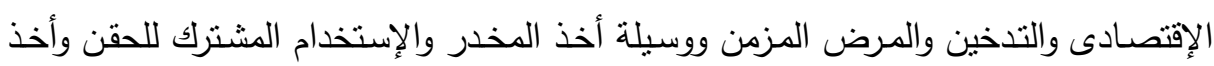

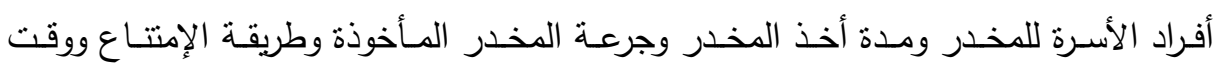
الإنتكاس كان لها تأثير أقل على نوعية الحياة.

دارسة ستيف سسمان (Sussman, 2001) الكثف عن الأماكن التي يفضل الفرد

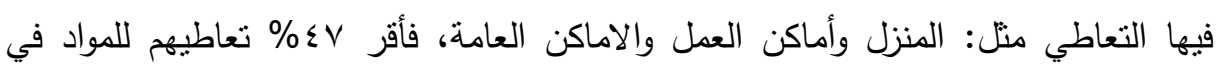

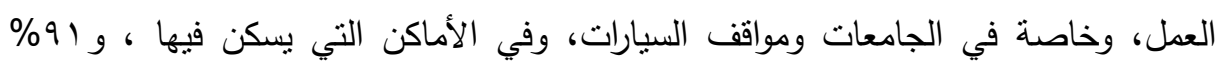

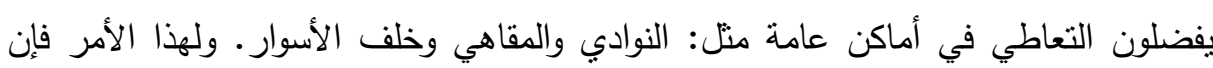

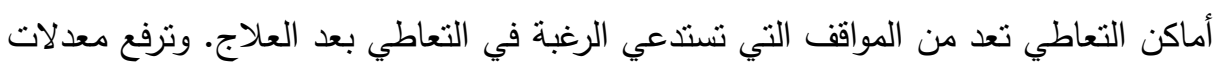

الانتكاسة.(Sussman, 2001).

دراسة عبدالله عسكر 1990 1: بعنوان "غياب الدعم الأسري وعلاقته بالانتكاسة بهدف

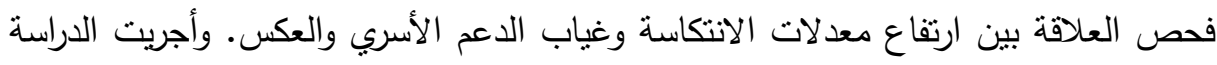

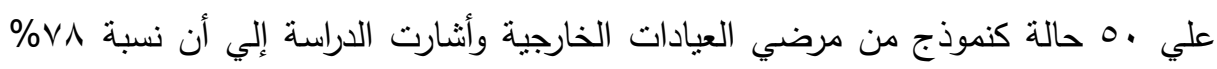

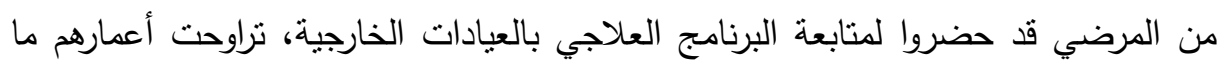

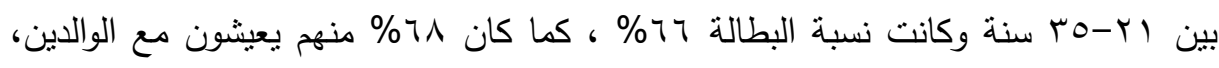

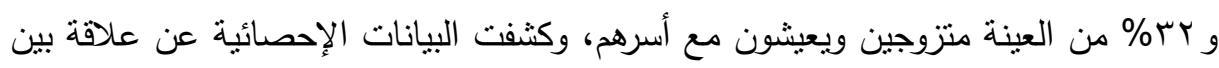


غياب الاعم الأسري من خلال إنكار الأهل لمشكلة أبنائهم أو رفض الزيارات خشية العار ، أو عدم المشاركة في جلسات العلاج الأسري. وبين ارتفاع معدلات الانتكاسة. المحور الثالث: دراسـات تناولت برامج التأهيل النفسي والإجتمـاعى وتحسين التهين نوعيه الحياة لاى المتعافين بعد العلاج من الإدمان. كما قام Gross Man بدراسة: للتعرف على البرامج المقدمة لمدمنى المخدرات 1990 وتقييم تلك البرامج للتعرف على مدى فاعليتها، وأوضحت نتائج الدراسة أنه لابد من الارتقاء

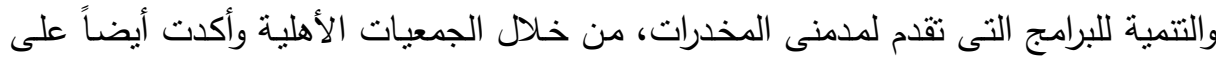

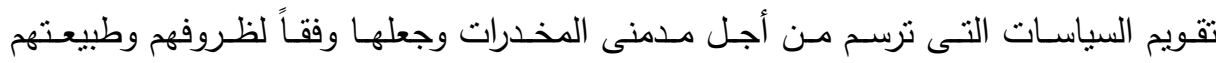

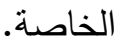

حيث أجري ين وانج وشين (yen,wang,\&chen 2011 دراسة هدفت إلى المقارنه بين متعاطين للهيروين وغير المتعاطين فى نوعية الحياة لفحص العلاقة بين نوعية الحياة

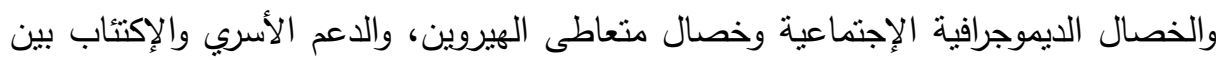

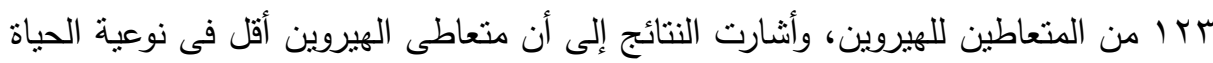
عن غير المتعاطين فى المجالات البدنية والنفسية والإجتماعية ولكن ليس في المجال البيئي حتى بعد ضبط نأثثر العوامل الأخرى، وتشير الدراسة إلى أن التخفيف من الأعراض الإكتأبية

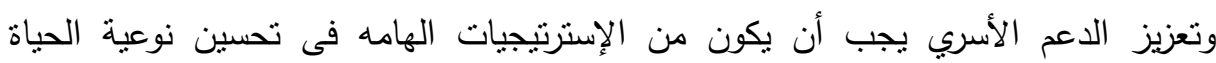

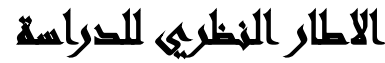

وتتعدد نظريات تفسير وحدوث الانتكاس من تفسيرات عضوية، واجتماعية بيئية، ونفسية، وسلوكية، ومعرفية انبتقت من مستويات مختلفة وتوجهات للتفسير العلمي حسب تبني كل متخصص لتوجيه العلمي، وسوف نستعرض هنا بعض نظريات تفسير الانتكاس ووجهة

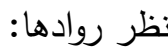




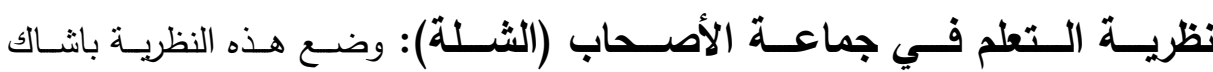

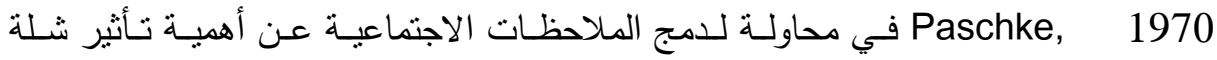

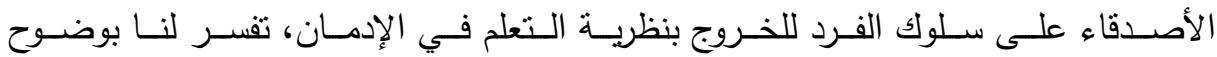

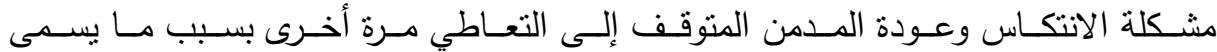

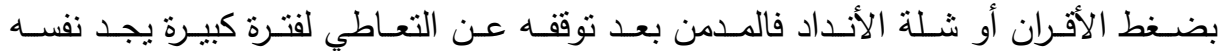

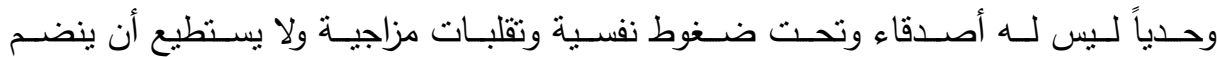
لأصدقاء جدد لهم معايير وقيم وسلوكيات مختلفة عن الأصدقاء القدامى. لهي.

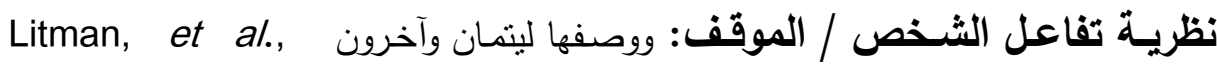

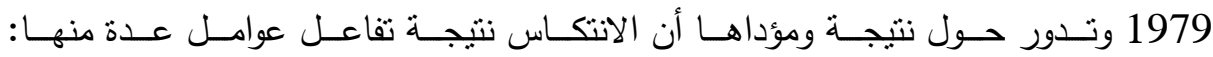

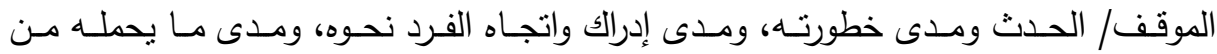

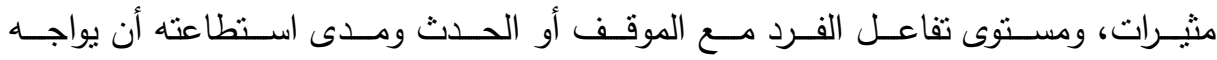

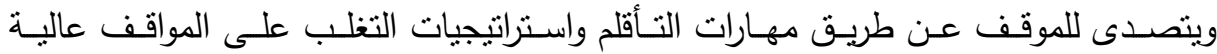

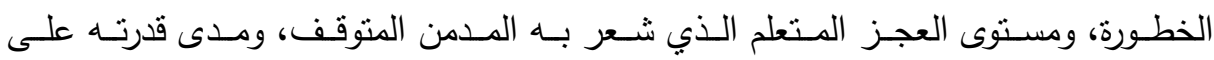
التصرف في المواقف ذات الخطورة العالية. نظرية الكفاءة الأتية: وصفها ألبرت باندورا Bandura, 1986 والتي اثتقت أساساً من

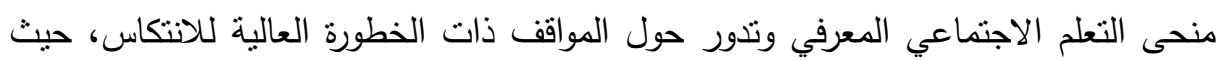

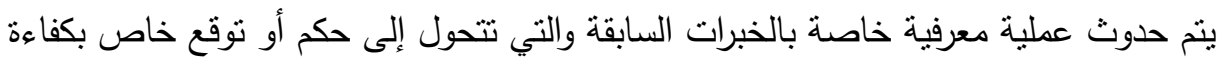
الددمن الدنوقف ومدى قدرته على التصدي ومواجهة الموقف والثأقلم معه وهذا الحكم الذاتي

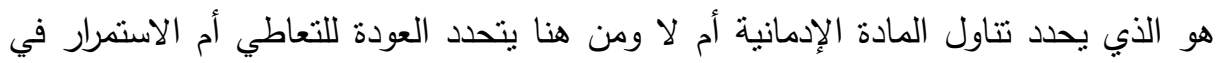
الامتناع. 


\section{الإيجاءائ المنهجية للتوراسة}

أولا: منهج الاراسة: المنهج المستخدم في هذه الدراسه هو المسح الاجتماعي بالعينة والذى يعتبر من أكثر المناهج العلميه شيوعا واستخداما في البحوث الإجتماعيه، وقد تم استخدام هذا

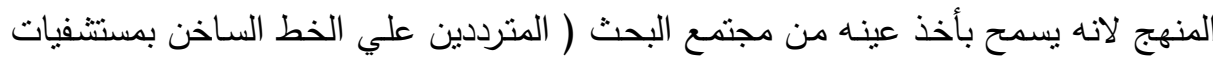

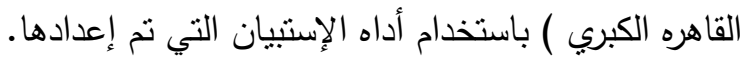

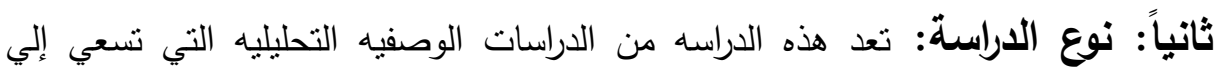
وصف مجتمع الدراسه وإستخدام التحليل بنوعيه ( الكمي - الكيفي) حيث أن الدراسات الوصفيه نوفر صوره دقيقه ومحدده لظاهره معينه، كما انها تساعد فى تحديد المكونات الاساسيه المؤديه إلى وصف وتتخيص وتحليل الظواهر في المجتمع للكثف عن المتغيرات الإجتماعيه والفيزيقيه لدي العائدين بعد التعافي من الادمان.

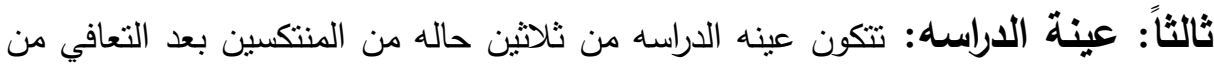

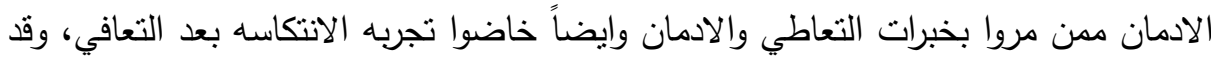
تم إختيار عينه الدراسه بطريقه عمديه من جانب الباحث من خلاد الأتي: - معرفه للتاريخ المرضي لكل حاله من الحالات - الاضرار والخسائر الناتجه عن تعاطى وإدمان المخدرات والتى تمثلت في بعض الاحيان في

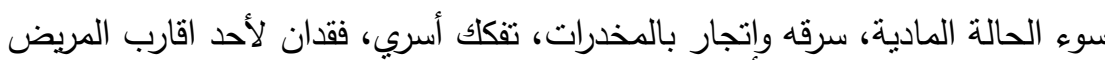
- أن يكون مر بخبره التعاطي ولا يقتصر علي نوع من المواد المخدره وقد ينعاطى هذة المواد

$$
\text { معاً فى وقت واحد. }
$$

- أن يكون قد نوقف عن التعاطي ولو لمره واحده ويفضل من تلقاء نفسه

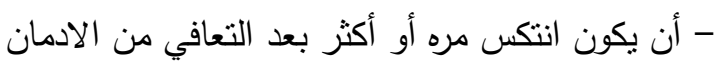

- من المترددين علي المستشفيات الثريكه مع الخط الساخن ومسجل بالسجلات الرسميه وقد تم اختيار سته حالات بارزه بطريقه عمديه لدراستها من خلال دليل المقابلة المتعقة

$$
\text { مع مراعاة الثروط التالية عند الإختيار: }
$$


- - - السن يتراوح ما بين 10 إلى ؛ ـ سنه - - تعاطي لأكثر من ماده مخدره ل- -

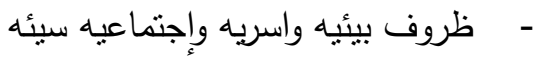

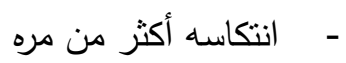

- - الرغبه الأكيده في العلاج هذه المره وعدم الرجوع للتعاطي مره أخري

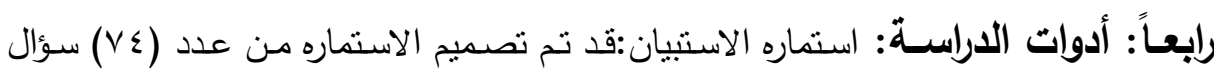
مقسمه إلي خمس محاور وهي: المحور الاول: بيانات حول السياق الإجتماعي للمبحوثين وتتضمن: • البيانات الاوليه للعينه ( الاسم والسن - الاقامه - الحاله الاجتماعيه - الحاله التعليميه الحاله العمليه أوالمهنيه - الدخل....) مكون من عدد ( 10 سؤال).

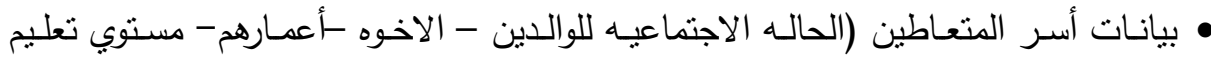
الوالدين - عمل الوالدين - تعاطي أحد أفراد الاسره للمخدرات) مكون من عدد( (1 سؤال)

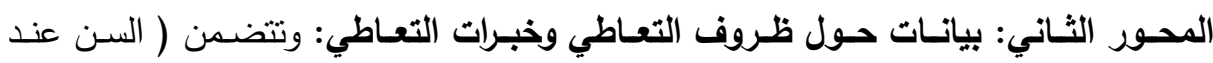
التعاطي - التجريب للمخدرات - السعي للحصول عليها - كيقيه قضاء وقت الفراغ- أسباب التعاطى - الاستمرار بالتعاطي مكان بدء التعاطى - مصادر الحصول علي المخدرات-

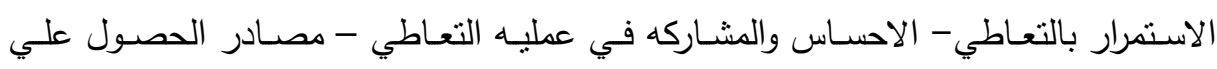
المخدرات - طرق التعاطى- التوقف عن التعاطى - الانتكاسـ- الاسباب التي أدت للعوده للتعاطي) والمحوركون من عدد ( O سؤال). المحـور الثالـث: بيانـات حـول الصــوره الذهنيـه الثـائعه تجـاه تعـاطي وإدمـان المخدرات ويتضمن: (وجهه نظر المبحوثيين حول المعتقدات والافكار الخاطئه والمرتبطه بتعاطي وادمان

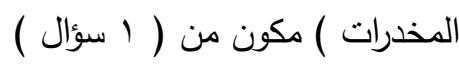
المحـور الرابـع: بيانـات حـول السـياق الفيزيقـي للمبحـوثين ويتضـمن ( مـدى توافرالمرافق والخدمات العامه ،طبيعه المنطقه - كثافه السكان - نوافر الخدمات سواء التعليميه أو صحيه لونيه أو الاهليه أوالدينيه أو الخدميه - السلوكيات الخاطئه الموجوده بالمنطقه. 
المحور الخـامس: إستبيان مسبيات الانتكاسـه : وهو من إعداد الباحث ويتكون من (v9)

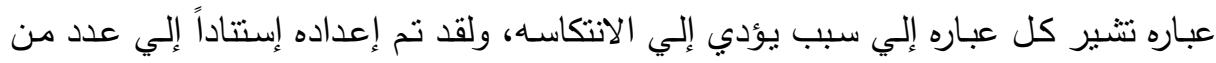

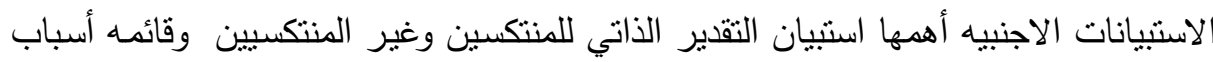
الانتكاسه ( asker \&Gundy , 1995). خامساً: صدق وثبات الإستبيان: الصدق: وهنا قام الباحث بعرض الاسنبيان علي مجموعه من الاساتذه المتخصصين في

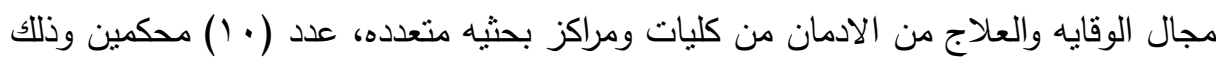

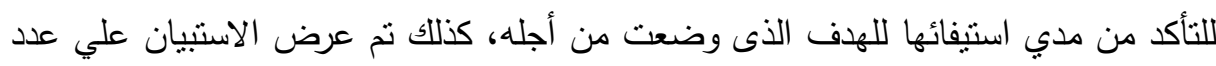

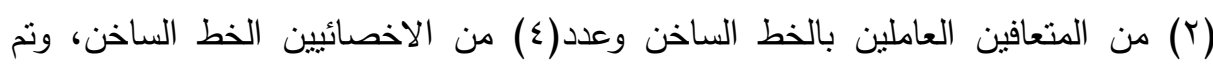
تقنيين الاسئله والتعديل بناءا علي الاسلوب والقواعد العلميه لإعداد وتصميم الاسنتيان وعليه

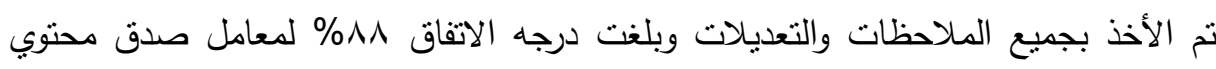
الاستبيان الثبات: وعليه قام الباحث بتوزيع الاستنيانات النهائيه علي عدد(0) متعافيين لهم نفس خصائص المنتكسين بمستشفي الديمرداش للصحه النفسبه، وبعد 10 يوم تم إعاده تطبيقها مره أخري ولم تظهر فروق تذكر بين الاستجابات في الحالتين . سادساً: مجالات الدراسة: 1-المجال البشري : نم إختبار عينه عددها • ب) مفرده من المترددين علي عيادات الخط

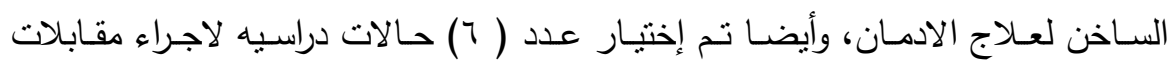
متعمقه معهم وفقاً لعده محكات. r-المجـال المكاني: تم التطبيق بعيادات الخط الساخن لصندوق مكافحه وعلاج الادمان بإقليم القاهره الكبري

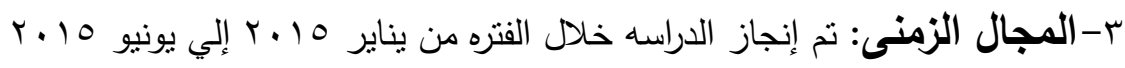




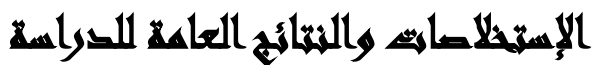

أولاً: إلي أى مدى توجد علاقه بين الخصائص الايموجرافيه لعينه الاراسه ودرجة انتكاسهم: جدول(1): العلاقه بين الحاله التعليميه ودرجة الإنتكاسه بعد التعافى من الإدمان.

\begin{tabular}{|c|c|c|c|c|c|c|c|c|c|c|}
\hline الالاله & كاب & \multicolumn{2}{|c|}{ الإجمالى } & \multicolumn{2}{|c|}{ منخفضه } & \multicolumn{2}{|c|}{ متوسطه } & \multicolumn{2}{|c|}{ مرتفعه } & \\
\hline \multirow{9}{*}{ غآل } & \multirow{9}{*}{.649} & $\%$ & ك & $\%$ & ك & $\%$ & ك & $\%$ & ك & \\
\hline & & 1. & $r$ & - & . & $1 V_{6} 7$ & $r$ & - & . & أمي \\
\hline & & $r$. & 7 & - & . & 11,1 & $r$ & $\leqslant \leqslant$ \& & $\varepsilon$ & يقرا ويكتب \\
\hline & & $r_{G}$ & 1 & - & . & 0.9 & 1 & - & . & ابتدائي \\
\hline & & 1. & $r$ & ro & 1 & 0,9 & 1 & 1161 & 1 & اعدادي \\
\hline & & $7 . \mathrm{V}$ & $\wedge$ & ro & 1 & $r r, 0$ & $\varepsilon$ & Tr.r & $r$ & تعليم منوسط \\
\hline & & $r_{6} T^{T}$ & V & 0. & $r$ & $r q, \varepsilon$ & 0 & - & - & فوق جامعي \\
\hline & & 7.6 & $r$ & • & - & 0.9 & 1 & 1161 & 1 & تعليم جامعي \\
\hline & & $1 \ldots$ & r. & $1 \ldots$ & $\varepsilon$ & $1 \ldots$ & IV & $1 \ldots$ & 9 & الإجمالى \\
\hline
\end{tabular}

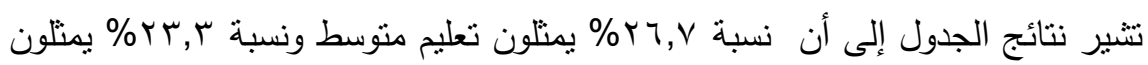

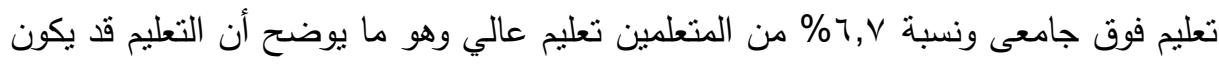
سبياً في وعي الثباب بفكرة العلاج والخروج من براثن المخدرات مع التسليم بأن الإنتكاسة جزء نعاء

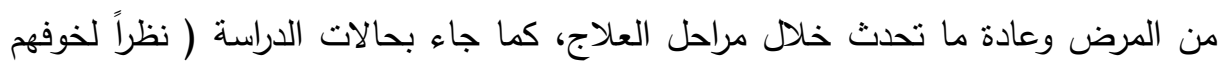

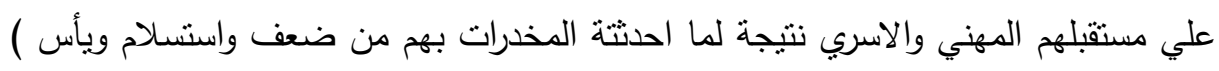
ونلاحظ عدم وجود علاقه بين الحالة التعليمية ودرجة الانتكاسة، نظراً لأن الانتكاسة كأحد

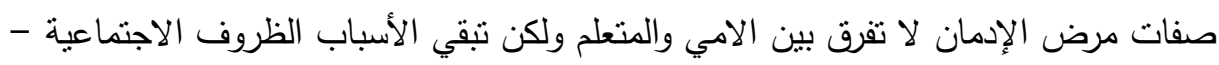

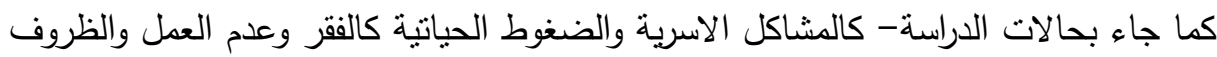

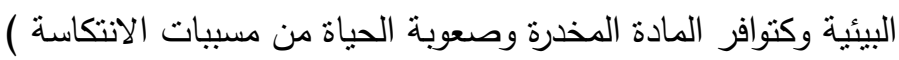


جدول(ץ): العلاقه بين الحاله المهنيه ودرجة الإنتكاسه بعد التعافي من الإدمان.

\begin{tabular}{|c|c|c|c|c|c|c|c|c|c|c|}
\hline الدلاله & SL & \multicolumn{2}{|c|}{ الإجمالى } & \multicolumn{2}{|c|}{ منخفضه } & \multicolumn{2}{|c|}{ متوسطه } & \multicolumn{2}{|c|}{ مرتفعه } & \\
\hline \multirow{7}{*}{ دال } & \multirow{7}{*}{$\cdot, 0 \leq$} & $\%$ & ك & $\%$ & ك & $\%$ & ك & $\%$ & ك5 & \\
\hline & & $\Gamma \varepsilon, 7$ & 9 & ro & 1 & YA, T & $\varepsilon$ & 0. & $\varepsilon$ & حرفى \\
\hline & & $10, \varepsilon$ & $\varepsilon$ & ro & 1 & $1 \leqslant, \Gamma$ & $r$ & $M r, 0$ & 1 & عامل خدمات \\
\hline & & $10, \xi$ & $\varepsilon$ & 0. & $r$ & $v, 1$ & 1 & $1 r, 0$ & 1 & موظف \\
\hline & & $10, \varepsilon$ & $\varepsilon$ & . & $\cdot$ & $Y \wedge, T$ & $\varepsilon$ & $\cdot$ & $\cdot$ & سائق \\
\hline & & $V, V$ & $r$ & . & . & $V, 1$ & 1 & $1 Y, 0$ & 1 & أعمال حره \\
\hline & & $1 \ldots$ & YT & $1 \ldots$ & $\varepsilon$ & $1 \ldots$ & $1 \leq$ & $\ldots$ & $\Lambda$ & الإجمال \\
\hline
\end{tabular}

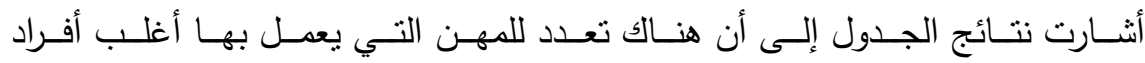

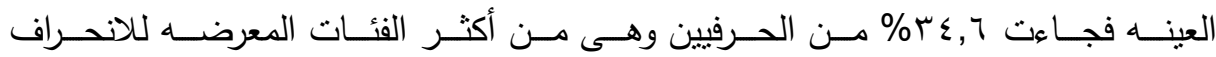

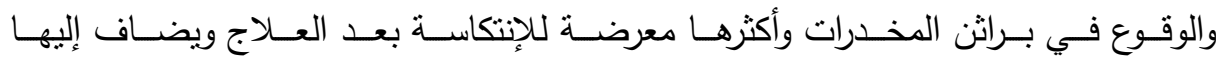

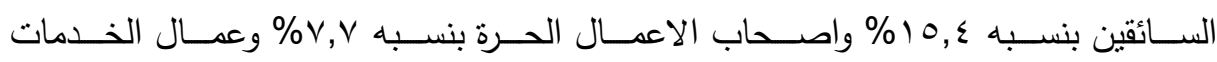

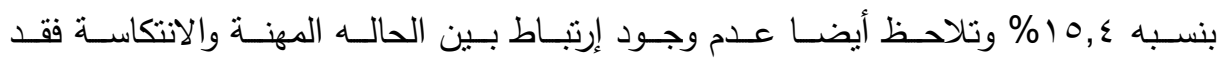

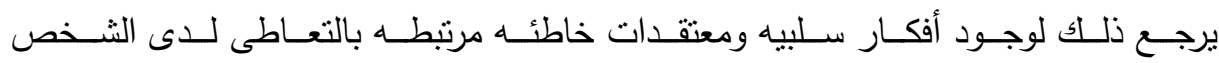

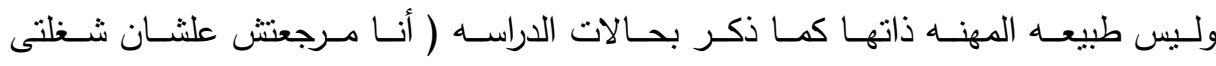

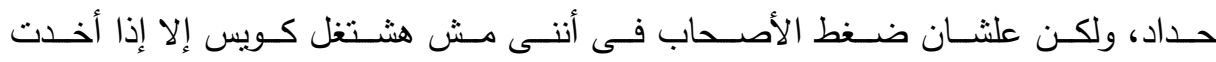
(البرشام) ثالثاً: إلى أى مدى توجد علاقة بين المعتقات الخاطئة والثشائعة عن المخدرات لاي العائدون للتعاطي ودرجة انتكاسهم بعد التعافى من الإدمان.

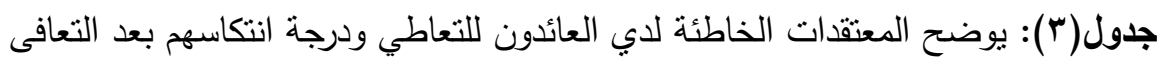

\begin{tabular}{|c|c|c|c|c|c|}
\hline الالدالة & SL & | النسبة\%ة\% & التكرار & الاستجابة & م \\
\hline داله & $\cdot, \cdot r$ & 9. & TV & المخدرات بتخلى الواحد يشتغل كويس & 1 \\
\hline داله & $\cdot, .0$ & $07, V$ & IV & المخدرات بتزود الميل إلي العملية الجنسية & r \\
\hline 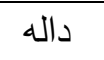 & $\cdot, \cdot r$ & $\overline{V r, r}$ & rY & المخدرات بتتسي الواحد الهموم والمشاكل & r \\
\hline داله & $\cdot, .0$ & $\Gamma \cdot$ & 9 & (البانجو - الحشيش) مش إدمان & $\varepsilon$ \\
\hline
\end{tabular}


1-أثنارت نتائج الجدول السابق إلى أن هناك الكثير من المعتقدات الخاطئة المرتبطة بأذهان

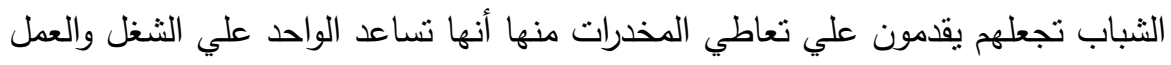
بايجابية ونشاط بنسبة ، 9\%، وأن غياب المخدر يجعلهم يعجزون عن العمل أو يفقدهم التركيز، كما جاء بدراسات الحالة في أن المخدرات (بتخليني انتغل كويس وخاصنة البرشام، مش بحس بأي تعب ولا إرهاق ...)، وتلاحظ وجود علاقة بين أن المخدرات

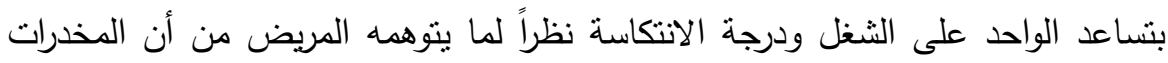

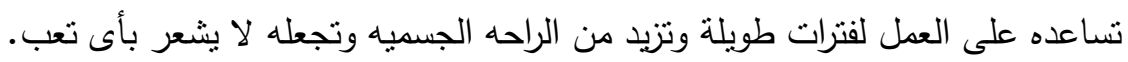

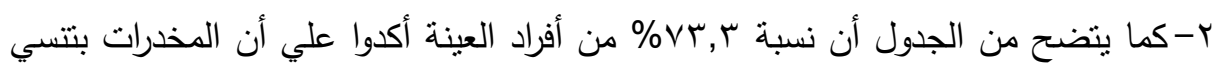
الهموم والمشاكل. وهذا أوردته دراسات الحالة في أن (المخدرات بتتسي الهموم والمشاكل اللي عايشنها سواء بالبيت أو الثغل أو المنطقة) فهم يجدون بالمخدرات الملجأ للنسيان

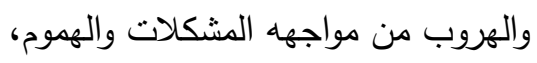

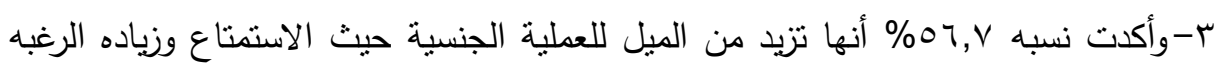
والميل للعمليه الجنسيه وهذا ما جاء ببعض دراسات الحالة فكانوا ( يتعاطون المخدرات

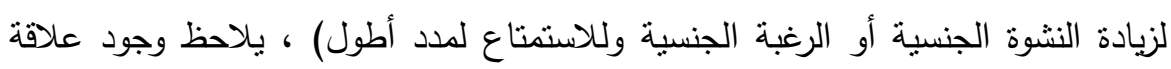

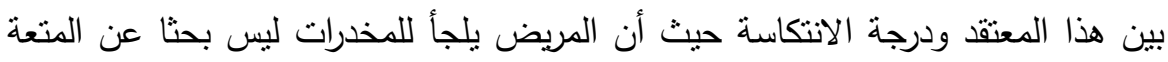
أو الاداء الجنسي المتميز الذي كان يتمتع به قبل ذلك بل أيضا ليشبع رغبته في إثبات رجولته .

ع- جاء أيضاً بالجدول أن هناك نسبه .r\% أن البانجوا والحشيش مش إدمان قد يرجع ذلك

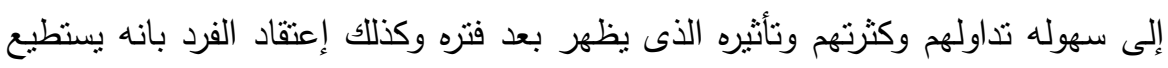

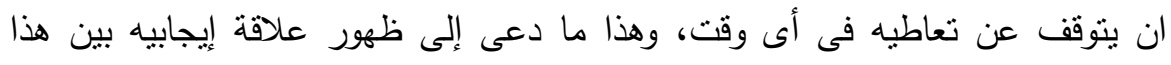

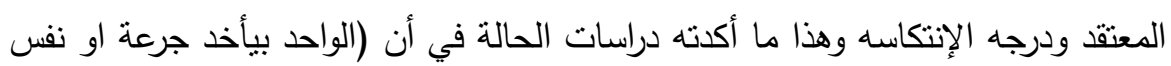
أو ليقضي ليلة زوجيه سعيدة فبرشامة واحدة وخلاص، يا عم جرعه واحده مش هنأثز ). 
رابعـاً: إلـى أى مـدى توجد علاقـة بـين مسبيات الانتكاسـه لـدي العائدين للتعـاطي ودرجـة انتكاسهم بعد العلاج من الإدمان إنان جدول( ) ): المتوسط العام مواقف ومسبيات الانتكاسه

\begin{tabular}{|c|c|c|c|}
\hline النسبه \% & المتوسط العام للفاعليه & مواقف ومسببات الإنتكاسه & 3 \\
\hline 90 &., 90 & الهفه والإشتياق للمخدر & 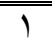 \\
\hline 19 & $\cdot, \wedge 9$ & المشاعر الساره المصاحبه للتعاطي & $r$ \\
\hline$\Lambda \Lambda$ & $\cdot, \wedge \wedge$ & ضغوط رفقاء السوء & r \\
\hline 10 & $\cdot, \wedge 0$ & المشاعر غير الساره المصاحبه للتعاطى & $\varepsilon$ \\
\hline A. & $\cdot, \wedge$. & المشكلات الاسربـه & 0 \\
\hline$V T$ & $\cdot, \mathrm{V} \mu$ & الأمراض النفسيه والبدنيه & 7 \\
\hline OV &., $0 \mathrm{~V}$ & إضطراب العلاقه بالآخرين & $\mathrm{V}$ \\
\hline & $0,7 \mathrm{~V}$ & إجمالى المتوسط العام لمواقف الإنتكاسـه & \\
\hline
\end{tabular}

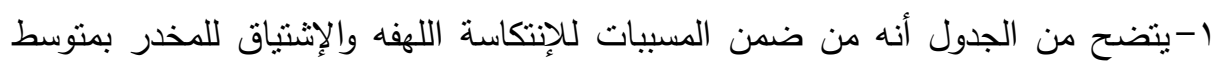
90\%، والتى تحدث نتيجة عرض الماده المخدره بسهوله علي المتعاطي، كذلك رؤيه المواد المخدره والتعامل معها، وأيضا المرور بأماكن بيع المخدرات منل الدواليب، ولعل ورود هذا العامل - عامل اللهفة والإثتناق - بالمرتبه الاولي إنما يدل علي أن هناك والك

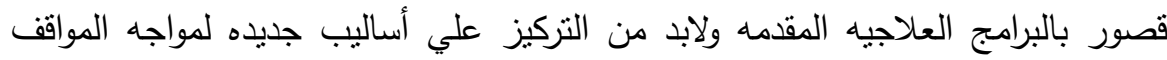
شديده الخطوره في هذا الملمح، مع الإهتمام بالمهارات الإجتماعيه ورفع الكفايه الذاتيه لدي لدي لئي المريض مع التدريب المتواصل علي كيفيه التعامل مع مواقف الإثتياق واللهفه علي

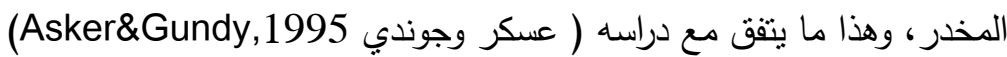

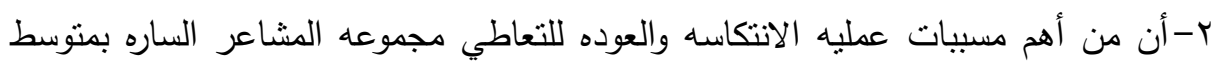

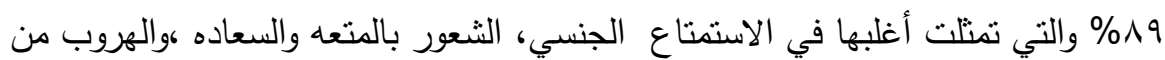
الواقع واللجوء إلي التخيلات الساره ،كذلك رفع مستوي المزاج، ويرجع ذلك لكون المنعاطي إكتسب خبره الشعور باللذه والسرور من جراء تعاطيه ،وإرتبطت لديه ذكريات التعاطي

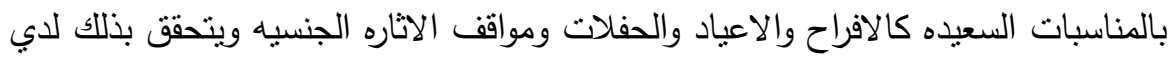
المتعاطى الارتياح والهدوء النفسي ،ويحتاج دوما إلي مساعد خارجي للقيام بمهمه الاستمتاع ،وهو في هذا يفتقد الاحساس الطبيعي باللذه فلا يسنطيع أن يعايش المتعه 


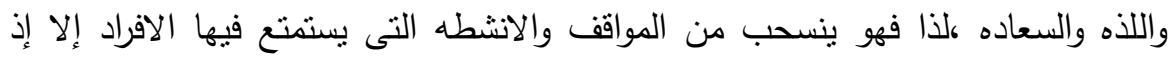

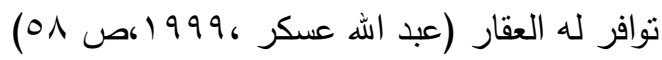
r-تشير نتائج الجدول أن عامل ضغط رفقاء السوء والمروجيين من أخطر العوامل وأنثدها

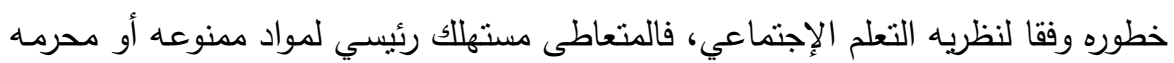
ولهذا لا يفكر المروج أو التاجر في خسارته ( أي خساره المتعاطي أو المدمن )، كما جاء

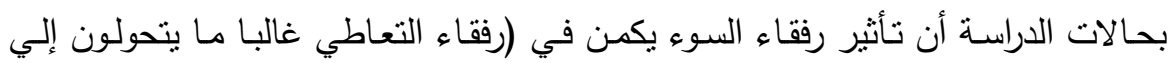
تجار وهروجين كي يستطيعوا تأمين المواد التي يتعاطونها ،وكذلك سبطره فكره مره واحده

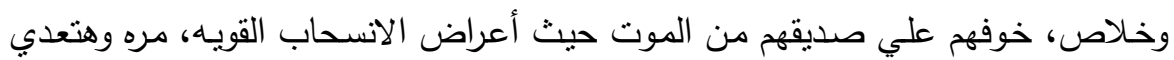

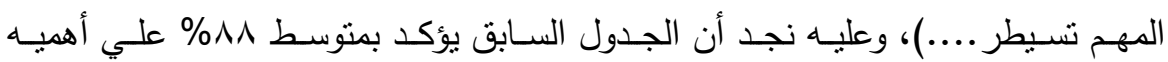

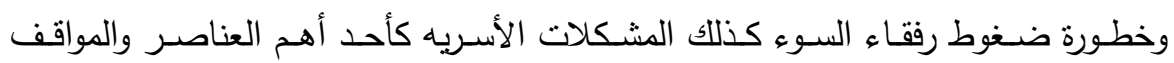
المسببة للإنتكاسة جاءت بمتوسط ، ^\% مما يؤكد على أهمية الدعم الاسري في العلاج حيث الإهتمام والرقابه والقدره علي مواجهه مثل هذه المشكلات وتداعياتها. ع- أسهوت مجموعه المشاعر غير السارة (بمتوسط ه10\%) بدرجة كبيره فى حدوث الانتكاسه

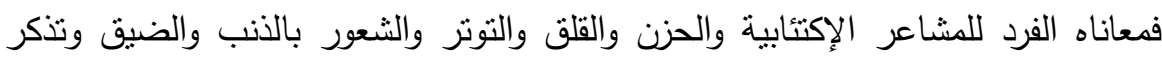

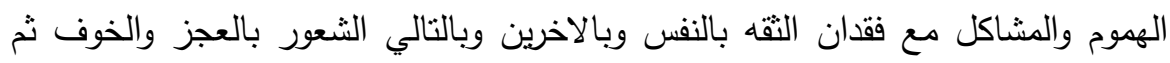

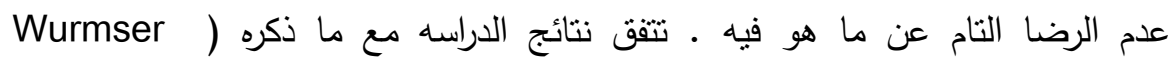

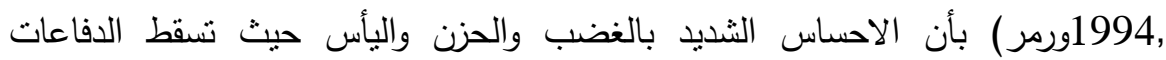
الوجدانيه التي لا تكون كافيه للإحتفاظ بقدر من المشاعر الوجدانيه الداخليه ثم يختفي الامل في الخروج من دائره التوتر الذي يتطور للبحث عن حل خارجى حيث يلجأ ثانياً إلي لئي

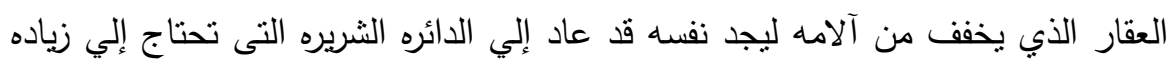

$$
\text { الجرعه وتجريب أكثر من عقار للخروج من المأزق. }
$$

ه-كذلك المشكلات الأسريه كأحد أهم العناصر والمواقف المسببة للإنتكاسة جاءت برد بمنوسط

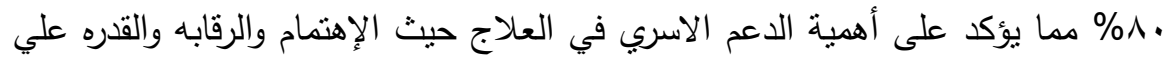

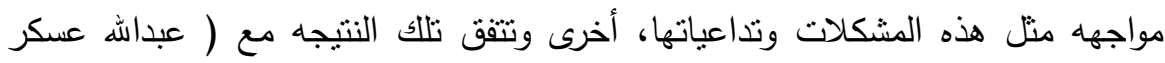


وأحمد البراك ،9901190) في كون الدعم الاسري لبرامج منع الانتكاسه يؤدي إلي إرتفاع

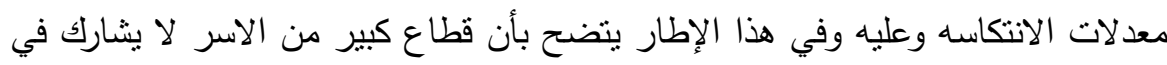
برامج العلاج الاسري المقدم، أو أن تلك البرامج في حاجه إلي مراجعه وتعديل.

\section{التحوبرامت}

أولاً: متغير التدريب والتأهيل (سواء للعاملين أو القائمين على تقديم الخدمسه العلاجيه أو حتى للمرضى ذاتهم) من خلال: 1- أهيــة تـدريب العـاملون بمجـال عـلاج الإدمـان وتزويــهم بالمهـارات التقنيـة الأساسـية والمعارف المجددة اللازمة لزيادة كفائتهم المهنية من أجل رعاية المدمنين وأسرهم وتأهيأهم اجتماعياً ونفسياً ودمجهم في المجتمع مرة أخرى بشكل فعال إيجابي منتج.

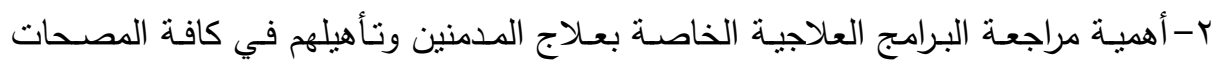

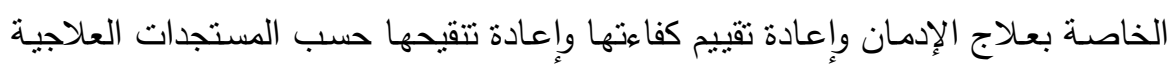
والوقائية والتأهيلية العالمية في هذا المجال. r- على المعالج أن يستخدم الأسـاليب والمهارات الحيانيـة فى نعليم المتعافى كيف يواجهة مشكلاته بالطرق الايجابية والسليمة بعيداً عن المخدرات.

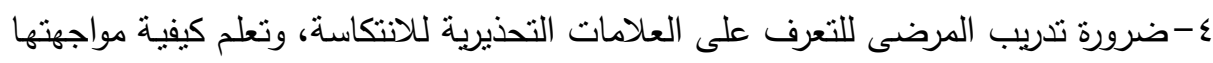
والتعامل معها عند حدوثها وأهم الاستراتيجيات المستعملة في الوقاية من الانتكاسة تشمل أساليب الدعم الاجتماعي وأساليب التغييرات الحياتية والأساليب المعرفية السلوكية. ثانياً:المتغير الفيزيقى والمجتمعى فى مواجهة ثقافه المخدرات من خلال:

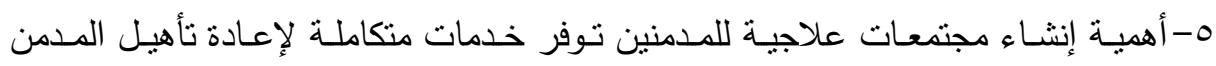
ودمجه في المجتمع مرة. צ- أهمية التتسيق بين الجهات الحكومية والأهلية لتوفير فرص عمل للمدمنين المتعافين أثناء

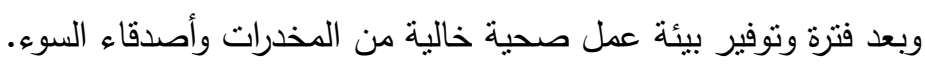


V-الإهنمام بمجموعة الادوار التي تقوم بها المؤسسات الدينية بالبيئه المحيطة بالأفراد من

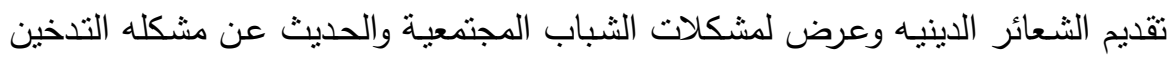

$$
\text { والمخدرات. }
$$

ثالثاً: المتغير الأسري للحد من الإنتكاسة والرجوع للتعاطى من خلال:

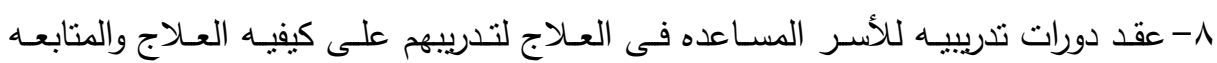

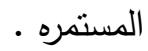

9-الاهتمام بإنشراك أسر المدمنين في البرامج العلاجية والتأهيلية لضمان حماية المدمن من الانتكاس وتوفير البيئة الاجتماعية الصحية له. • 1 -تفهم الخطوات الوقائيه والعلاجيه علي نحو علمي من خلال خفض الصنيه الصراعات الاسريه والاهتمام بالمريض وتدعيم علاجه ومنحه التقه مع عدم الإفراط في القسوه أو التدليل الذائد

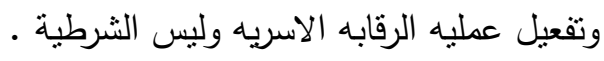

\section{رابعاً: المتغير الثقافي للحد من التعاطى ومن ثم الإنتكاسة الإنه من خلال:}

ا إزاله الإعتقاد بصعوبة العلاج والتأهيل والدمج المجتمعى فالعديد من مرضى الإدمان

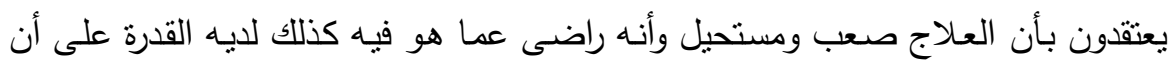
يتوقف من تلقاء نفسـه فى أى وقت وهنا تكمن خطورة تلك الأفكار فى جعل الإنتكاسـة أسهل. r ا - أهمية تعديل الاعتقادات اللاعقلانية مع تخفيف مشاعر الذنب والخزي التي تؤدي إلى الذى

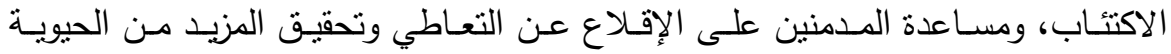

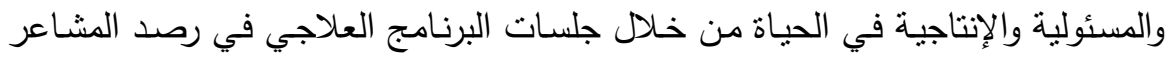
السلبية التى تؤدي إلى الانتكاس وتبديل الأفكار السلبية بأخرى إيجابيـة والتدريب على ولى

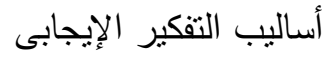


مجلة العلوم البيئية

معهد الدراسات والبحوث البيئية - جامعة عين شمس البه

$$
\begin{aligned}
& \text { zall }
\end{aligned}
$$

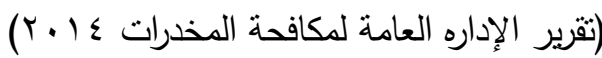

$$
\begin{aligned}
& \text { جمعه يوسف(ץ . . ץ): الوقاية من تعاطى المخدرات، القاهرة، دار الغريب للنشر ص10 } \\
& \text { دليل الأخصائي النفسي في الوقاية والعلاج من الإدمان والتعاطي( ل. . ب): القاهرة . }
\end{aligned}
$$

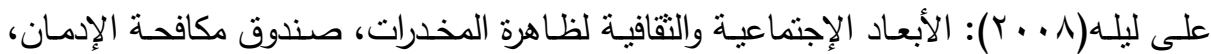

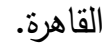

$$
\begin{aligned}
& \text { عبداله عسكر ( . . †): الإدمان بين النتخيص والعلاج،القاهرة، مكتبه الأنجلو المصرية. } \\
& \text { مجدى جرس(T + . ץ): الإدمان والإيدز - كاريناس - مصر ، القاهرة . } \\
& \text { محمد سـامة غباري(999 (19): الإدمان أسبابة ونتائجه وعلاجه، الإسكندرية، المكتب الجامعي مهندي }
\end{aligned}
$$

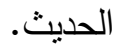

$$
\begin{aligned}
& \text { مصطفي سويف (799 (1)): المخدرات والمجتمع نظرة نكاملية ، الكويت ، سلسلة عالم المعرفة. }
\end{aligned}
$$

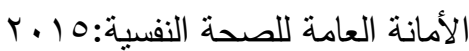

$$
\begin{aligned}
& \text { محمد ياسر الخواجة(r + . ץ): الانحراف والمجتمع(طنطا، دارالمصطفى للنشر والتوزيع. }
\end{aligned}
$$

Asker, A.\& Gundy, G.(1992):The Differences in the reasons \& relapse between young and adult opiate inpatients addicts. The Egyptian Journal of Mental Health, Cairo, 36.67-86

Gross man-Susan ; Joy , An Alcohol and drug prevention program Evaluation( London, Beverly Hills ,1995 ) p. 106.

Jones Zgrabben, the social works with addiction (London: British library, 1995)p.2

Miller, Hester. (1989) Treating alcohol Problems: Toward an informed electisism, in W. R. Miller and R. K. Hester, Handbook of alcoholism treatment approaches: Effective alternatives. New York: Per gammon Press.

Majer ,John(2003):.by,www.findarticles.com

$$
\text { المجلا الثالث والثالثون، الجزء الأول، يونيو } 7 \text { ـ }
$$


علي ليله وآخرون

Sussman, Steve (2001):Self- reported high- risk locations of drug use among drag offenders, American journal of drug and Alcohol abuse, by:www.findarticles.Com

\title{
SOCIAL AND PHYSICAL VARIABLES FOR THOSE RELAPSING FROM ADDICTION TREATMENT A FIELD STUDY ON A SAMPLE OF RELAPSING YOUTH
}

Laila, A. ${ }^{(1)}$; Ahmed, Laila, A. ${ }^{(2)}$; Hany, A. F. ${ }^{(3)}$ and Askkar, I. A. ${ }^{(4)}$ 1) Faculty of Arts, Ain Shams University, 2) The National Center of Social and Criminal Researches 3) Institute of Environmental Studies Research, Ain shams University 4) Fund of Confronting and Treating Addiction

\begin{abstract}
The present study amis to reveal the social and physical factory prevailing and leading to the setback and the order of these factors by gravity as well as the detection of common factors and differentiated according to the variables of the demographic of the sample the type of used medicine, duration of drug abuse, the take-off and the number of times setback roughly to achieve this goal, the researcher choose the thirtieth case of both sexes under age 15-40 years with different educational, occupational and environmental levels to apply all the questionnaire prepared by the researcher, then choose six cases in intentional manner to be case of study, the study relied on the descriptive approach, social survey and used tools including questionnaire from and in - depth interview. the results showed that there is:

1. Relapse as one of the addictive disease's attributes .it doesn't differentiate between someone is educated and someone is not

$$
\text { المجلد الثالث والثلاثون، الجزء الأول، يونيو } 1 \text {. ب r }
$$


but the social circumstances, life pressure like poverty and unemployment and environmental factors remains one of the causes of relapse.

2. - The Craftsmen are the most categories which is being exposed to the deviation and they have more chances of being addictive than the others and exposing to relapse after treatment and this may count on the negative thinking and wrong beliefs Owned to an addict.

3. There are lots of wrong beliefs connected with youth's beliefs which encourages drug use like it improves their work performance in account for 90 percent and drug shortage make them unable to work and less focus and forget about worriers in account for 73.3 percent and 56.7 improve the sex ability and account for 30 that Marijuana/ Hashish is not addiction.

4. Longing and desires are one of the reasons in account 95 and good feelings which is happening due to the easy way to get the drugs also seeing the drugs and dealing with it and being where the drug is and feel good and happy.

5. The environmental factors like events and social revolution and new culture and beliefs have the main role in relapse where feel fearing from future and disability and then unsatisfaction about him.

6. The family's problems are one of the most important component and the situations causes relapse in account for $80 \%$ which confirm the value of family's support in cure where concern ,observation and the ability to face such as these problems and it's consequences. 